\title{
ChemComm
}

\section{Rational linkage of magnetic molecules using click chemistry $\dagger$}

Cite this: Chem. Commun., 2015, 51,6524

Received 21st January 2015,

Accepted 9th March 2015

DOI: $10.1039 / \mathrm{c} 5 \mathrm{cc00595g}$

www.rsc.org/chemcomm

CUAAC click reactions were used for the first time to assemble click-functionalized magnetic molecules into extended molecular arrangements in a deliberate manner.

Single-molecule magnets ${ }^{1}$ (SMMs) show magnetic hysteresis of purely molecular origin and thus are proposed for trendsetting applications like quantum computing or ultra-high density memory devices. ${ }^{2,3}$ In particular the quantum entanglement of molecular magnets using a weak antiferromagnetic coupling is proposed as an excellent approach to perform quantum information processing. ${ }^{3,4}$ Impressive examples include antiferromagnetically coupled $\mathrm{Mn}_{4} \mathrm{SMMs}^{5,6}$ where tuning of the quantum tunneling of magnetization was successfully investigated ${ }^{5}$ and the persuasively demonstration that $\mathrm{Cr}_{7} \mathrm{Ni}$ molecular wheels can be covalently assembled in a rational way. ${ }^{7}$ In spite of the large number of SMMs present in the literature, examples of covalently linked metal complexes are rare. Apart from the few achievements with coupled $\mathrm{Cr}_{7} \mathrm{Ni}$ rings and $\mathrm{Fe}_{2} \mathrm{M}$ clusters $(\mathrm{M}=\mathrm{Ni}, \mathrm{Co})^{8}$ the linkage of magnetic molecules to defined molecular assemblies in a rational manner is still in its infancy.

To overcome this problem we present here an innovative new approach using click reactions to link magnetic molecules. Since its report in $2001^{9}$ click chemistry has been used in almost all key areas of synthetic chemistry. ${ }^{10}$ Interestingly, up to now the only known example of a clearly successful click reaction with polynuclear complexes is the decoration of $\mathrm{Ru}_{2}$ clusters with organic dendrons. ${ }^{11}$ However, on our view the $\mathrm{Cu}(\mathrm{I})$-catalyzed Huisgen cycloaddition between azide and alkyne (CuAAC) ${ }^{12}$ is entirely suitable for covalently linking magnetic building blocks

\footnotetext{
${ }^{a}$ Institut für Anorganische und Analytische Chemie, Johannes

Gutenberg-Universität Mainz, Duesbergweg 10-14, 55128 Mainz, Germany.

E-mail: rentschl@uni-mainz.de; Fax: +49-6131-39-23922

${ }^{b}$ Graduate School Materials Science in Mainz, Staudinger Weg 9, D-55128 Mainz, Germany

$\dagger$ Electronic supplementary information (ESI) available: Experimental details, X-ray crystallography with further structural views, detailed spectroscopic and magnetic data. CCDC 910513. For ESI and crystallographic data in CIF or other electronic format see DOI: 10.1039/c5cc00595g
}

a)

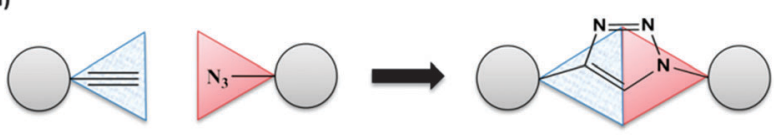

b)

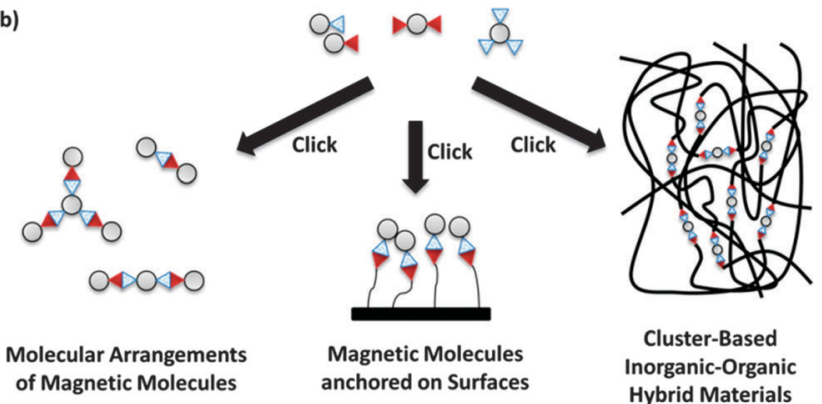

Fig. 1 Schematic representation of click chemistry as innovative method for the linkage of MBBs. (a) Magnetic molecules (grey dots) are linked together using the CuAAC. (b) Overview of potential applications.

(MBBs) which bear appropriate functional groups (Fig. 1a). The process selectively leads, under mild conditions, to a 1,4-disubstituted 1,2,3-triazole as a conjugated bridge, which even guarantees magnetic communication between two or more MBBs.

Our strategy for the synthesis of MBBs is to use ligands with additional non-coordinating functional groups in the periphery to prepare functionalized derivatives of proven mono- or polynuclear complexes. To realize defined molecular assemblies the following points have to be considered: the number of introduced modified ligands must be limited to prevent an overloading of the complex, and, most crucial, the structural integrity of the complex in the reaction solvent is required. This has to be ensured by checking with suitable methods like NMR spectroscopy and mass spectrometry. Following this new approach, supramolecular arrangements of magnetic molecules can be achieved with a maximum degree of control and flexibility, while preserving the structure and the fundamental magnetic properties of the MBBs. It is worth mentioning that this click concept can be used further in other promising research fields of molecular magnetism such as covalent anchoring 


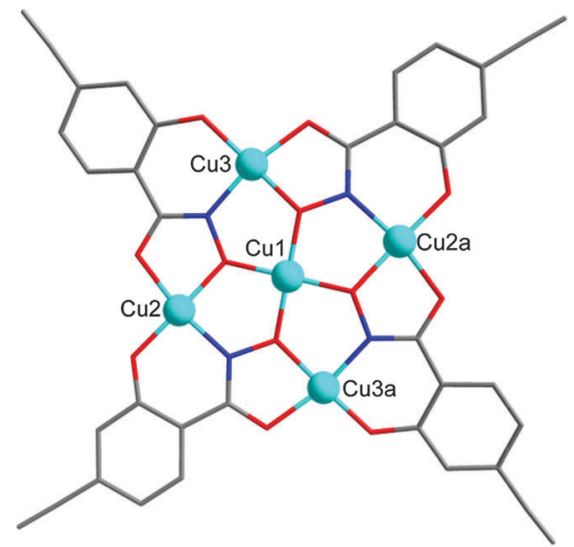

Fig. 2 Molecular structure of $\left[\mathrm{Cu}^{\prime \prime}\left(12-\mathrm{MC}_{\mathrm{Cu}(\mathrm{IIN}) \mathrm{N}(\mathrm{eshi})}\right)^{-4)}\right]^{2-}$ (1). Symmetryequivalent positions are denoted by an "a". Hydrogen atoms are omitted for clarity and only selected atoms were labeled. Grey (C), red (O), dark blue (N).

of SMMs on surfaces to attain an applicability of them ${ }^{13}$ or to develop new cluster-based inorganic-organic hybrid materials (Fig. 1b). ${ }^{14}$

Here we present alkyne-functionalized salicylhydroxamic acid based 12-MC-4 metallacrowns as paramagnetic building blocks. For non-functionalized copper complexes, the structural integrity has been shown by Pecoraro and co-workers. ${ }^{15}$ As this is an important precondition for suitable PBUs we synthesized the fourfold alkyne-functionalized complex (TMA $)_{2}\left[\mathrm{Cu}^{\mathrm{II}}\left(12-\mathrm{MC}_{\mathrm{Cu}(\mathrm{II}) \mathrm{N}(\mathrm{eshi})}-4\right)\right]$ (1) (TMA = tetramethylammonium) in high yield from 4-ethynylsalicylhydroxamic acid $\left(\mathrm{H}_{3} \mathrm{eshi}\right)$. In the centrosymmetric pentanuclear copper complex 1 (Fig. 2) each of the copper ions shows an almost square planar coordination geometry. $\ddagger$ The peripheral four copper ions are bridged by $\mathrm{N}-\mathrm{O}$ groups of the deprotonated ligand eshi $^{3-}$ forming a 12-membered metallacrown ring which encapsulates one central $\mathrm{Cu}(\mathrm{II})$ ion. Complex $\mathbf{1}$ is nearly planar and the four alkyne groups protrude from the cluster orthogonal to each other.

To prove structural integrity in solution NMR spectroscopy was used. Although the compound is paramagnetic and copper(II) complexes usually give spectra of no use due to slow electronic relaxation, unequivocal $1 \mathrm{D}$ and 2D NMR spectra are obtained for 1. Presumably in our case the magnetic coupling between the metal ions increases the relaxation times and allows for a reasonable use of the NMR technique. ${ }^{16}$ The ${ }^{1} \mathrm{H}$ NMR solution spectrum of complex 1 (Fig. 3 ) in $\mathrm{d}_{6}$-DMSO shows four NMR signals for the metallacrown anion as a result of the $C_{4 \mathrm{~h}}$ symmetry in solution. According to the ${ }^{1} \mathrm{H}-{ }^{1} \mathrm{H}$ COSY spectrum (see Fig. S5, ESI $\dagger$ ) the signals at 5.70 and $7.23 \mathrm{ppm}$ are correlated and are thus assigned to the two neighboring protons $3-\mathrm{H}$ and 4-H. The signal assignment of the remaining protons is based on the assumption that the paramagnetic effect is stronger for a shorter $\mathrm{Cu}-\mathrm{H}$ distance. The broad signal at $7.23 \mathrm{ppm}$ with a line width of $26 \mathrm{~Hz}$ is assigned to $3-\mathrm{H}$ based on the short crystallographically determined average $\mathrm{Cu}-\mathrm{H}$ distance of $4.8 \AA$ A. Assigning the narrow signal at $5.70 \mathrm{ppm}$ with a line width of $10 \mathrm{~Hz}$ to the proton $4-\mathrm{H}$ is in accordance with a larger $\mathrm{Cu}-\mathrm{H}$ distance of $6.5 \AA$. The relatively sharp signal at $4.17 \mathrm{ppm}$ can clearly be assigned to the acetylene proton in the periphery. The remaining signal is hence assigned to 6-H. The structural integrity of $\mathbf{1}$ in solution is therefore confirmed. Moreover, ESI MS studies also prove evidence of the complex 1 in solution. The measured peak at $\mathrm{m} / \mathrm{z}=506.3$ (Fig. 4) in a DMSO-MeOH solvent matrix corresponds to a fully intact $\left[\mathrm{Cu}^{\mathrm{II}}\left(12-\mathrm{MC}_{\mathrm{Cu}(\mathrm{II}) \mathrm{N}(\mathrm{eshi})}-4\right)\right]^{2-}$ ion. The magnetic properties of $\mathbf{1}$, investigated by dc susceptibility measurements, are similar to those reported for non-functionalized copper metallacrowns. ${ }^{15,17}$ The $\chi_{\mathrm{m}} T$ value of $0.41 \mathrm{~cm}^{3} \mathrm{~K} \mathrm{~mol}^{-1}$ at $2 \mathrm{~K}$ corresponds to an isolated $S=1 / 2$ ground spin state and is explained by the observed strong antiferromagnetic coupling between the $\mathrm{Cu}(\mathrm{II})$ ions (see ESI $\dagger$ ).

Once we had confirmed complex 1 being a suitable MBB, various reactions were performed proving its ability as reagent for the CuAAC. All click reactions were run in $\mathrm{d}_{6}$-DMSO with copper iodide as catalyst (Scheme 1). Reactions of 1 with 1-azidoadamantane and phenylazide at $80{ }^{\circ} \mathrm{C}$ led to the new copper

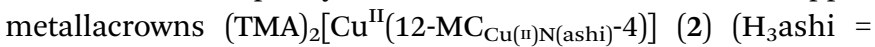
4-(1-adamantyl-1 $H$-[1,2,3]triazol-4-yl)salicylhydroxamic acid) and

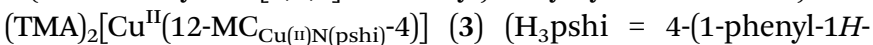
$[1,2,3]$ triazol-4-yl)salicylhydroxamic acid), respectively. The process was monitored using NMR spectroscopy and the reaction found to be completed after $24 \mathrm{~h}$ for both, 2 and 3. The ${ }^{1} \mathrm{H}$ NMR spectrum of 2 (Fig. 3) shows the disappearance of the acetylene signal and a simultaneous increase of a signal at $8.35 \mathrm{ppm}$, arising from the emerging triazole proton. The assignment of the remaining protons was made analogous to complex 1. ESI MS studies show intact $\mathbf{M}^{2-}$ ions at $m / z=861.7$ for 2 and $m / z=$ 745.4 for 3 (Fig. 4), confirming the success of the click reaction. The UV-Vis spectra of both compounds are in good agreement with the spectrum of $\mathbf{1}$ with typical $\mathrm{d}-\mathrm{d}$ absorption maxima between 616 and $620 \mathrm{~nm} .{ }^{15}$ The magnetic susceptibility data of complexes 2 and 3 (Fig. S12, ESI $\dagger$ ) are in accordance with the molecular structures of pentanuclear copper metallacrowns (see ESI $\dagger$ ). The successful syntheses of extended copper metallacrowns unambiguously verify the potential of copper metallacrowns to perform click reactions.

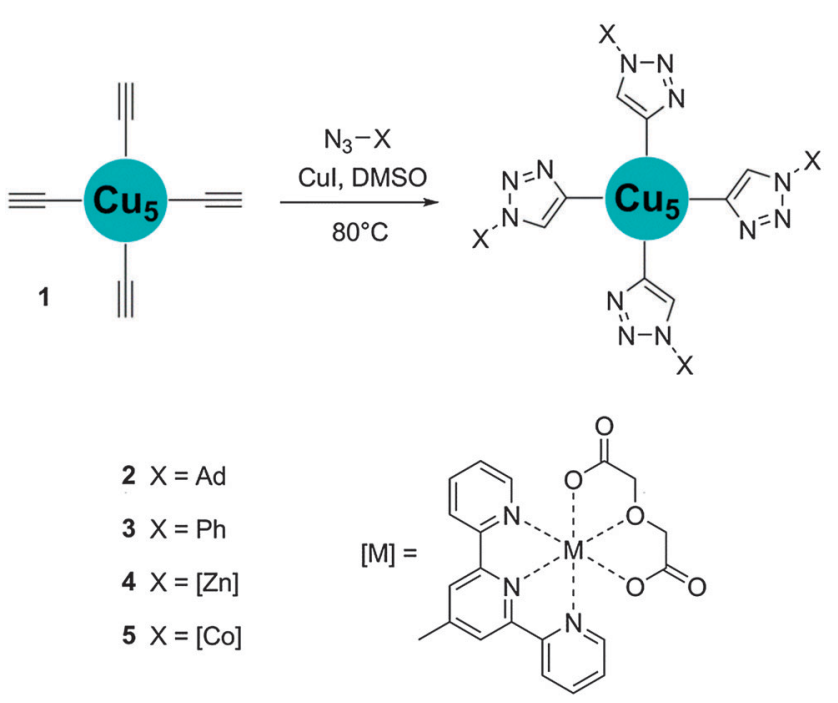

Scheme 1 Synthesis of extended copper metallacrowns by CuAAC. 

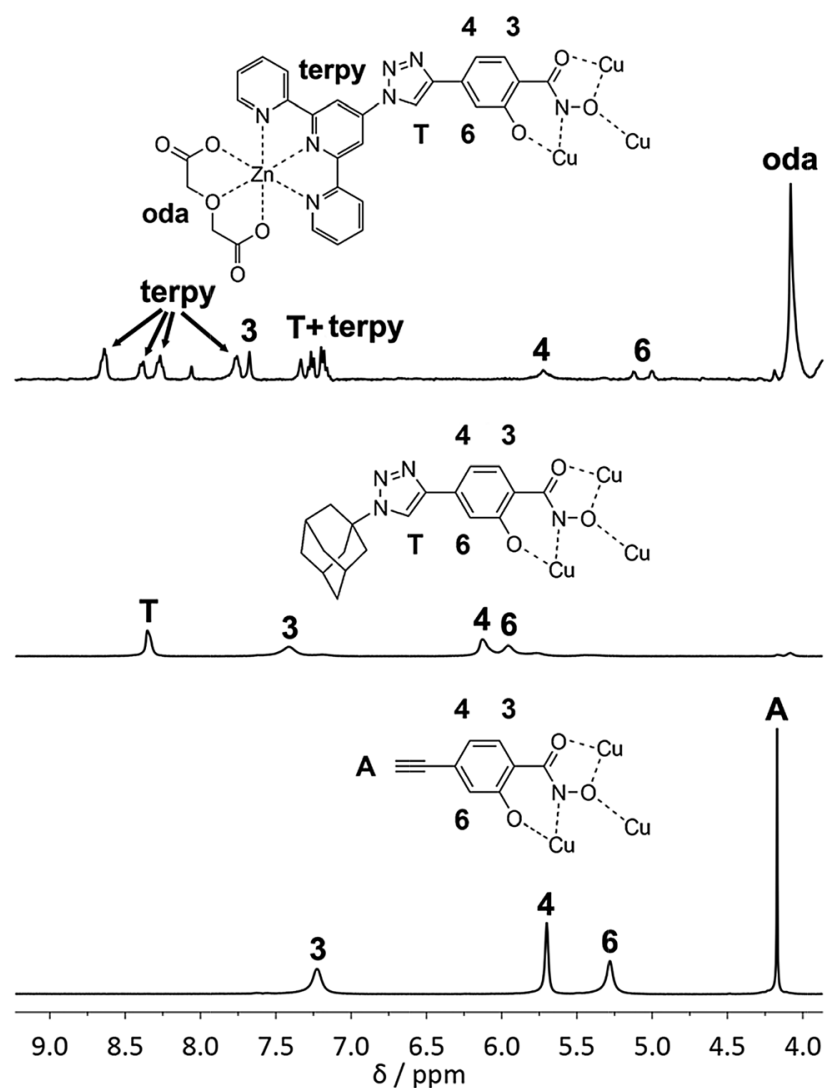

Fig. $3{ }^{1} \mathrm{H}$ NMR spectra and assignment $(\mathrm{A}=$ acetylene, $\mathrm{T}=$ triazole, oda $=$ oxodiacetate, terpy $=$ terpyridine) for complexes $\mathbf{4}, \mathbf{2}$ and $\mathbf{1}$.

Consequently, we applied the established click concept for the first time to connect SMMs in a deliberate manner (Scheme 1). The copper metallacrown 1 was used as scaffold to get nonanuclear arrangements with the azide-functionalized complexes $[\mathrm{M}($ oda $)($ aterpy $)]$ (oda = oxodiacetate, aterpy $=4^{\prime}$-azido- $2,2^{\prime}: 6^{\prime}, 2^{\prime \prime}$-terpyridine) with $\mathrm{M}=$ $\mathrm{Zn}$ and Co. We recently reported the two click-functionalized building blocks and discussed the SMM behavior of the mononuclear cobalt complex in detail. ${ }^{18}$ Reaction of the building

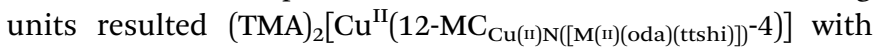

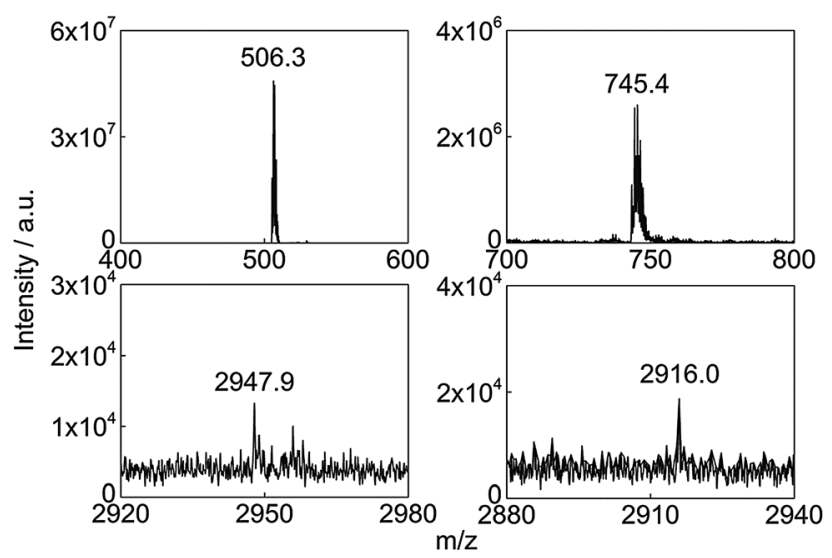

Fig. 4 ESI-MS(-) spectra of 1 (top left, $[M]^{2-}$ ion), $\mathbf{3}$ (top right, $[\mathrm{M}]^{2-}$ ion), 4 (bottom left, $[\mathrm{M}+2 \mathrm{Na}]^{-}$ion) and $\mathbf{5}$ (bottom right, $[\mathrm{M}+2 \mathrm{Na}]^{-}$ion).
$\mathrm{M}=\mathrm{Zn}$ (4) and Co (5) $\left(\mathrm{H}_{3} \mathrm{ttshi}=4-\left(2,2^{\prime}: 6,2^{\prime \prime}\right.\right.$-terpyridyl- $1 H^{-}$ $[1,2,3]$ triazol-4-yl)salicylhydroxamic acid). As expected for the $\mathrm{Cu}_{5} \mathrm{Zn}_{4}$ complex 4 with additional diamagnetic zinc units, ${ }^{1} \mathrm{H}$ NMR studies were possible and the disappearance of the acetylene signal indicated completeness of the reaction in $\mathrm{d}_{6}$-DMSO after $48 \mathrm{~h}$. Assignment of the ${ }^{1} \mathrm{H}$ NMR signals (Fig. 3) was done with help of the COSY NMR spectrum (Fig. S10, ESI $\dagger$ ). Intact $[\mathrm{M}+2 \mathrm{Na}]^{-}$ions in the ESI MS spectra at $m / z=2947.9$ for 4 and $m / z=2916.0$ for 5 (Fig. 4) provide the evidence for the successful click reactions in both cases. The infrared spectra, UV-Vis spectra and preliminary magnetic studies support this. The $\chi_{\mathrm{m}} T$ value of $0.34 \mathrm{~cm}^{3} \mathrm{~K} \mathrm{~mol}^{-1}$ at $2 \mathrm{~K}$ of the $\mathrm{Cu}_{5} \mathrm{Zn}_{4}$ complex 4 is in a good agreement with the values of the $\mathrm{Cu}_{5}$ metallacrowns 1-3 $\left(0.41,0.31\right.$ and $0.29 \mathrm{~cm}^{3} \mathrm{~K} \mathrm{~mol}^{-1}$, respectively), indicating fairly strong exchange interactions. Due to orbital contributions of $\mathrm{Co}(\mathrm{II})^{19}$ in the $\mathrm{Cu}_{5} \mathrm{Co}_{4}$ complex 5 the $\chi_{\mathrm{m}} T$ value of $13.10 \mathrm{~cm}^{3} \mathrm{~K}$ $\mathrm{mol}^{-1}$ at $300 \mathrm{~K}$ (Fig. S26, ESI $\dagger$ ) is significantly higher than the calculated value of $9.38 \mathrm{~cm}^{3} \mathrm{~K} \mathrm{~mol}^{-1}$ for five non-interacting $\mathrm{Cu}$ (II) ions with $S=1 / 2$, four non-interacting $\mathrm{Co}$ (II) ions with $S=3 / 2$ and $g=2.0$. The observed decrease of $\chi_{\mathrm{m}} T$ on cooling is typical for antiferromagnetic interactions within the $\mathrm{Cu}_{5}$ core as well as for spin-orbit coupling effects of cobalt ions. ${ }^{19}$ Therefore, fitting of the $\chi_{\mathrm{m}} T$ data was not attempted to avoid over-parameterization.

However, Ac susceptibility measurements of complex $\mathbf{5}$ reveal a weak out-of-phase signal at low temperatures and low field oscillation frequencies (Fig. S14, ESI $\dagger$ ). The observed slow relaxation of magnetization possibly indicates preserving of SMM behavior in the assembled $\mathrm{Cu}_{5} \mathrm{Co}_{4}$ compound, although the presence of small amounts monomeric cobalt SMM cannot be ruled out entirely.

In conclusion, we report the first example of a successful linking of magnetic molecules using CuAAC click chemistry to synthesize a $\mathrm{Cu}_{5} \mathrm{Co}_{4}$ complex as a novel magnetic arrangement of different MBBs. For this purpose we have synthesized an alkyne-functionalized copper metallacrown which is a highly suitable MBB for click reactions. The structural integrity in solution as a key property as well as the fundamental reactivity has been proven in great detail.

\section{Notes and references}

† Crystallographic data for $2 \cdot 2 \mathrm{H}_{2} \mathrm{O}: \mathrm{C}_{44} \mathrm{H}_{44} \mathrm{Cu}_{5} \mathrm{~N}_{6} \mathrm{O}_{14}, M=1198.56$, crystal size: $0.36 \times 0.19 \times 0.05 \mathrm{~mm}^{3}$, monoclinic, space group $P 2_{1} / n$, $a=6.2137(14) \AA, b=16.2226(36) \AA, c=22.6452(48) \AA, \beta=91.2531(53)^{\circ}$, $V=2282.1(9) \AA^{3}, T=173(2) \mathrm{K}, Z=2, \rho_{\text {calcd }}=1.744 \mathrm{~g} \mathrm{~cm}^{-3}, 25686$ reflections collected, 5407 unique $\left(R_{\mathrm{int}}=0.057\right), R_{1}=0.038, \mathrm{w} R_{2}=0.113$ using 3885 reflections with $I>2 \sigma(I)$.

1 R. Sessoli, D. Gatteschi, A. Caneschi and M. A. Novak, Nature, 1993, 365, 141-143.

2 (a) M. N. Leuenberger and D. Loss, Nature, 2001, 410, 789-793; (b) M. Affronte, J. Mater. Chem., 2009, 19, 1731-1737.

3 F. Troiani and M. Affronte, Chem. Soc. Rev., 2011, 40, 3119-3129.

4 F. Meier, J. Levy and D. Loss, Phys. Rev. B: Condens. Matter Mater. Phys., 2003, 68, 134417.

5 W. Wernsdorfer, N. Aliaga-Alcalde, D. N. Hendrickson and G. Christou, Nature, 2002, 416, 406.

6 L. Lecren, O. Roubeau, C. Coulon, Y.-G. Li, X. F. Le Goff, W. Wernsdorfer, H. Miyasaka and R. Clérac, J. Am. Chem. Soc., 2005, 127, 17353. 
7 G. A. Timco, T. B. Faust, F. Tuna and R. E. P. Winpenny, Chem. Soc. Rev., 2011, 40, 3067-3075.

8 (a) P. Alborés and E. Rentschler, Dalton Trans., 2010, 39, 5005-5019; (b) P. Alborés, C. Plenk and E. Rentschler, Inorg. Chem., 2012, 51, 8373-8384.

9 H. C. Kolb, M. G. Finn and K. B. Sharpless, Angew. Chem., Int. Ed., 2001, 40, 2004-2021.

10 (a) J. E. Moses and A. D. Moorhouse, Chem. Soc. Rev., 2007, 36, 1249-1262; (b) M. Meldal and C. W. Tornøe, Chem. Rev., 2008, 108, 2952-3015; (c) D. Schweinfurth, R. Pattacini, S. Strobel and B. Sarkar, Dalton Trans., 2009, 9291-9297.

11 W. P. Forrest, Z. Cao, W.-Z. Chen, K. M. Hassell, A. Kharlamova, G. Jakstonyte and T. Ren, Inorg. Chem., 2011, 50, 9345-9353.

12 V. V. Rostovtsev, L. G. Green, V. V. Fokin and K. B. Sharpless, Angew. Chem., Int. Ed., 2002, 41, 2596-2599.
13 A. Cornia, M. Mannini, P. Sainctavit and R. Sessoli, Chem. Soc. Rev., 2011, 40, 3076-3091.

14 U. Schubert, Chem. Soc. Rev., 2011, 40, 575-582.

15 B. R. Gibney, D. P. Kessissoglou, J. W. Kampf and V. L. Pecoraro, Inorg. Chem., 1994, 33, 4840-4849.

16 I. Bertini, C. Luchinat and G. Parigi, Solution NMR of paramagnetic molecules, Applications to metallobiomolecules and models, Elsevier Science Ltd, Amsterdam, New York, 2001, vol. 2.

17 (a) C. McDonald, T. Whyte, S. M. Taylor, S. Sanz, E. K. Brechin, D. Gaynor and L. F. Jones, CrystEngComm, 2013, 15, 6672-6681; (b) P. Happ and E. Rentschler, Dalton Trans., 2014, 43, 15308-15312.

18 C. Plenk, J. Krause and E. Rentschler, Eur. J. Inorg. Chem., 2015, 370-374.

19 F. Lloret, M. Julve, J. Cano, R. Ruiz-García and E. Pardo, Inorg. Chim. Acta, 2008, 361, 3432-3445. 